\title{
Patterns of seed bank and size asymmetry of plant growth across varying sites in the invasive Lantana camara $L$. (Verbenaceae)
}

\author{
Olusegun O. Osunkoya $\cdot$ Christine Perrett • \\ Chandima Fernando $\cdot$ Cameron Clark
}

Received: 29 August 2012/ Accepted: 28 March 2013/Published online: 1 May 2013

(C) Crown Copyright as represented by: State of Queensland, Department of Agriculture, Fisheries and Forestry, Australia 2013

\begin{abstract}
Lantana camara L. (Verbenaceae) is a weed of great significance in Australia and worldwide, but little is known about connections among components of its life history. We document over a 3-year period, the links between $L$. camara seed-bank dynamics and its above-ground growth, including size asymmetry in four land-use types (a farm, a hoop pine plantation and two open eucalypt forests) invaded by the weed near Brisbane, Queensland Australia. Seedbank populations varied appreciably across sites and in response to rainfall and control measures, and they were higher $\left(\sim 1,000\right.$ seeds $\left./ \mathrm{m}^{2}\right)$ when annual rainfall was $15-30 \%$ below the long-term yearly average. Fire reduced seed-bank populations but not the proportion germinating (6-8\%). Nearly a quarter of fresh seeds remain germinable after 3 years of soil burial. For small seedlings $(<10 \mathrm{~cm}$ high $)$, the expected trade-offs in two life-history traits-survival and growth-did not apply; rather the observed
\end{abstract}

O. O. Osunkoya $(\bowtie) \cdot$ C. Perrett · C. Fernando .

C. Clark

Department of Agriculture, Fisheries and Forestry, Ecosciences Precinct, Invasive Plant Science Group,

Biosecurity Queensland, GPO Box 267, Brisbane,

QLD 4001, Australia

e-mail: olusegun.osunkoya@daff.qld.gov.au

C. Fernando

Queensland Biosecurity Control Centre, Oxley,

Brisbane, QLD 4067, Australia positive association between these two traits, coupled with a persistent seed-bank population could contribute to the invasiveness of the plant. Relationships between absolute growth rate and initial plant size (crown volume) were positively linear, suggesting that most populations are still at varying stages of the exponential phase of the sigmoid growth; this trend also suggests that at most sites and despite increasing stand density and limiting environmental resources of light and soil moisture, lantana growth is inversely size asymmetric. From the observed changes in measures of plant size inequality, asymmetric competition appeared limited in all the infestations surveyed.

Keywords Australia - Biological-invasions · Lantana camara $\cdot$ Seed-bank - Seed germination . Growth rates · Gini coefficient - Size inequality · Weeds

\section{Introduction}

Seed traits, plant growth and their variabilities play important roles in population persistence. For example, a persistent and dense seed bank gives assurance during unfavourable reproductive episodes of continued recruitment, thus stabilizing population numbers and influencing the evolution of plant life histories (Baskin and Baskin 2000; Gioria et al. 2012). Hence, 
soil seed bank dynamics of which are affected by environmental factors such as recurring fire or precipitation, together with seed source and dispersal mode, play significant roles at various stages in vegetation dynamics, influencing the establishment success of either native or exotic species, with respectively positive or negative consequences for progressing ecological restoration (Zimmerman et al. 2000; Gioria et al. 2012).

In addition to seed dynamics and reproductive capacity, stand structure also affects a plant species establishment success. Information contained in a set of size measurements (height, diameter, and volume/ biomass) for a population of plants can be used to make inferences about past or present competitive environments within that population (Thomas and Weiner 1989; Weiner 1990; Vega and Sadras 2003; Dolezal et al. 2009; Metsaranta and Lieffers 2010; Pretzsch and Dieler 2011; Méndez-Alonzo et al. 2012). While there is a prevalence of such studies across many plant life forms and ecological groups, including forest and commercially utilized species, equivalent study on invasive plants as a group is scant (but see Arenas et al. 2002). However, such studies can shed light on the extent of size growth inequality (asymmetry) and competition in this group of organisms and might help explain mechanisms of their persistence and/or spread. For weeds, especially of perennial woody types in natural environments, we know very little about the interplay between population density, growth rate, size inequality and competition (see Arenas et al. 2002; Wiegard et al. 2005). For example, in woody invasive species, the phenomenon of asymmetric growth and competition, in which large individuals suppress the growth of smaller individuals by pre-empting a disproportionate share of environmental resources such as light in a forest understorey environment has rarely been investigated (but see Weiner 1990; Arenas et al. 2002).

Lantana camara L. (Verbenaceae) (lantana hereafter) is a perennial (longevity $>25$ years), thicketforming shrub native to South America (Swarbrick et al. 1995). As in many other shrub species, it is capable of vegetative regrowth following disturbance. In addition, it yields flowers and fruits profusely, and its succulent drupes (size: 3-5 mm) containing 1-2 seeds are dispersed by birds (Vivian-Smith et al. 2006). Lantana seeds have the capability for long-term persistence in the soil ( $>10$ years to reach $0 \%$ viability; Vivian-Smith and Panetta 2009), but germination of the buried seeds may often be triggered by disturbances such as fire or mechanical clearing (Raizada and Raghubanshi 2010). Lantana is ranked among the world's 100 most invasive species (Lowe et al. 2004), with structural capability to encroach on managed and disturbed natural forests as well as on agricultural lands (Gooden et al. 2009; Osunkoya and Perrett 2011). The present study, which is part of a long-term study of lantana whole-life cycle population dynamics in Australia (see Osunkoya et al. 2010; Osunkoya and Perrett 2011; Osunkoya et al. 2012, 2013), documents below (seed bank) and above-ground (stand) growth dynamics over a 3-year period in near-monospecific populations of the weed across four contrasting sites (in terms of land use) near Brisbane, Queensland, SE Australia.

The objectives are twofold. Firstly, to explore spatiotemporal variation in seed germination and the soil seed bank of lantana across various land-use types it invades, taking cognizance of prevailing environmental variables, especially light and precipitation. Within this objective and irrespective of sites, we hypothesized that the soil seed-bank population of the weed will be more abundant during drought as a result of enforced dormancy (Duggin and Gentle 1998; Sahu and Panda 1998). Also a lower seed-bank might be expected in a re-invasion phase following control via mechanical clearing or fire due to reduced plant abundance and vigour. Our second objective is to examine short-term (inter-annual) variability in the size asymmetry of growth amongst tagged individuals of lantana. The expectation was that, as in most plant species, asymmetry of growth would be manifested, but we seek to explore the consistency of the trend across invasion phases (established and recolonization stages) and in various land-use types. For infestations in a forest ecosystem, where light is often limiting, we hypothesized that large plants should consistently perform better than the smaller ones relative to what would be expected based solely on differences in size (thus accentuating asymmetric growth and intra-specific competition); such a trend may not necessarily be observable in a more open, agricultural landscape, where resource pre-emption, if any, would be more for below-ground resources (water and nutrients) that are difficult to monopolize and hence, growth will be more symmetric (Schwinning and Weiner 1998; Weiner and Damgaard 2006; Dolezal et al. 2009). We also hypothesized that short-term variability in size asymmetry will be increased by factors that increase productivity 
(e.g. high precipitation) in response to intense competition for growth (Metsaranta and Lieffers 2010).

\section{Methods}

Site description

The study was undertaken during 2008-2010 in the Yarraman and Blackbutt area, $200 \mathrm{~km}$ north-west of Brisbane in southeast Queensland, Australia. Comprehensive information on natural history, including climate, vegetation, soil chemistry and extent of lantana invasion of the study region and sites can be found in Osunkoya and Perrett (2011) and Osunkoya et al. (2012). Lantana plants of the white-flowered form are the dominant variety in this region. Threeyear rainfall data (2005-2007) prior to commencement of the project in 2008 indicated that rainfall during this period (574-620 mm/year) was 15-35\% below long-term yearly average (743-793 mm/year) in the region, typical of drought conditions. The drought event was over 1-2 years after our experimental plots were set up, as yearly rainfall records were at par with or well above the long-term average (2008: 681-691 mm; 2009: 700-898 mm; 2010: 1,296-1,367 mm; 2011: 1,085-1,289 mm-Australian Government Bureau of Meteorology).

\section{Lantana vegetation sampling and field data} collection

Demographic data were collected during the 3-year period (2008-2011) from permanent plots in lantana infestations that are in established and/or proliferation phases within four land-use types in the study region. Three of the infestation sites, each 5-10 km apart, were in Yarraman: (i) a cattle grazing property (farm), with ground vegetation cover consisting mainly of the fodder grass, Pennisetum claudestinum; (ii) a hoop pine (Arucaria cunninghamii) plantation; and (iii) an open eucalypt (dry sclerophyll) forest with a low triennial burning regime of the understorey vegetation by Queensland Plantation Forestry (QPF) to minimize fire outbreak into managed adjoining hoop pine plantations; we set up the plot in October 2008, 2 years after the September 2006 prescribed burning operation and the plot was again burnt a year after (i.e., in September 2009). In February 2008, 6 months prior to setting up the permanent plot at the hoop pine plantation (i.e., August 2008), the lantana infestation had been cleared, with appreciable soil disturbance during thinning operation of the pines by QPF, but there had been significant recolonization, mainly from the soil seed bank thereafter. The fourth site is in Blackbutt, $25 \mathrm{~km}$ from the nearest sampled site in Yarraman. This site is also an open eucalyptus forest managed by QPF and is occasionally grazed by cattle, but no fire regime is applied. Average $( \pm \mathrm{SE})$ recorded light levels as a percentage of full sunlight at these sites are of the order: farm $(100 \pm 0.82 \%)>$ burned forest $(45.0 \pm$ $5.2 \%)>$ plantation $(35.2 \pm 8.5 \%) \geq$ grazed forest $(25.5 \pm 3.2 \%)$ (see Osunkoya et al. 2012 for details).

In summary, the permanent plots were established in July, August, September and October 2008 for the hoop pine plantation, farm, grazed and burned forest, respectively. At these periods, specific areas $\left(1,500-2,500 \mathrm{~m}^{2}\right.$ per site) were delineated, searched repeatedly, and all lantana plants $>20 \mathrm{~cm}$ in height were permanently tagged with unique numbers on castiron labels, mapped and measured for height, crown depth and crown diameter in two dimensions (see Osunkoya et al. 2012 for measurement details). Mean $( \pm \mathrm{SE}) 10 \mathrm{~m} \times 10 \mathrm{~m}$ lantana stand densities at these sites were in the order: grazed forest $(96.5 \pm 8.34)>$ plantation $(57.21 \pm 31.97)>$ burned forest $(23.33 \pm$ $0.75) \geq$ farm $(13.81 \pm 1.43)$. The tagged plants were categorised into five size groups: seedlings $(10-20 \mathrm{~cm})$; juveniles (21-60 cm); small $(61-100 \mathrm{~cm})$; medium $(101-160 \mathrm{~cm})$ and large $(>161 \mathrm{~cm})$ "reproductive" adults. In February 2009, due to difficulty in relocation of very small-sized individuals in the field, 60 newly germinated (ex glasshouse) seedlings of lantana (2-4 weeks old; height $<10 \mathrm{~cm}$ and $1-2$ pairs of leaves) were transplanted randomly into the plot at each site, mapped, tagged and also monitored at 6-month intervals for rates of growth and survival for 2 years. The fate of all tagged individuals and new recruits in the plots was then followed annually in 2009 , 2010 and 2011 to document vital demographic rates. Month of the annual census varied across sites, depending on the date of initial plot setup (see above).

Seed bank and seed germination

In the surveyed years of 2008-2010, germination of freshly collected lantana seeds at each site $(n=200$ 
seeds from 5 to 10 fruit-bearing individuals collected in November-December of each survey year) was determined in a glasshouse in Brisbane where they were exposed, in germination trays filled with a commercial soil, to adequate moisture and temperature over a 12-month period (method similar to that in Vivian-Smith et al. 2006; Vivian-Smith and Panetta 2009). In addition, in November-December 2008 at each of the four sites, 15 lots of 100 ripe and freshly collected seeds of lantana from 10 plants were put into $20 \times 10 \mathrm{~cm}$ fine nylon mesh bags. The aperture of the mesh was about $0.25 \mathrm{~mm}^{2}$. Each bag was then filled with sieved (lantana-free) soil collected from the census plots, with content thoroughly shaken to ensure even distribution of the seeds. The seed bags were buried in random spots in the census plot at $5-10-\mathrm{cm}$ depth, which stimulate the natural burial depth of most dispersed seeds (Baskin and Baskin 2000; VivianSmith et al. 2006). Every 12 months, five bags were retrieved per plot. The contents of each bag were then washed in a sieve (of aperture size $0.30 \mathrm{~mm}^{2}$ ) with running water, and the remaining lantana seeds found were counted and tested for germination (emergence of radicle and/or production of first leaf pairs) by exposing the collected seeds in trays in a glasshouse for 9-12 months as described above. Once a year and coinciding with the annual census periods, ten soil core samples $(10 \mathrm{~cm}$ in diameter and $10 \mathrm{~cm}$ deep) were taken with a soil auger at random but close to reproductive adults at each site to estimate the lantana seed bank. These samples were taken to the laboratory, where they were passed through a series of fine-mesh sieves, and lantana seeds were extracted and counted using a stereo microscope. The extracted seeds were also exposed to adequate growth conditions (see above) to estimate their germinability.

\section{Data analyses}

Measured crown dimensions, assuming a cone shape, were converted to crown volume, using the expression $\left.1 / 3 \times \pi \times(W / 2)^{2} \times D\right)$ where $W=$ crown width, estimated as the average of maximum crown lengths and crown widths, and $D=$ crown depth.

Demographic data (plant growth and survival, seedbank abundance and germination) were checked for homoscedasticity and appropriate transformations carried out where needed before being subjected to ANOVA with site (4 levels) and census time ( 2 or 3 levels) or plant size group (5 or 6) as main factors, using SPSS version 20 software. Bar graphs, histograms, correlation and regression graphs were used to explore the trends in the data. Relative growth rate (RGR) of plant height (ht) and crown volume (crv) during 2008-2009 and in 2009-2010 survey periods were calculated as $\ln \left(\mathrm{ht}_{t_{2}}\right)-\ln \left(\mathrm{ht}_{t_{1}}\right) /$ $\left(t_{2}-t_{1}\right)$ and $\ln \left(\operatorname{crv}_{t_{2}}\right)-\ln \left(\operatorname{crv}_{t_{1}}\right) /\left(t_{2}-t_{1}\right)$, respectively, where $t$ is the time interval (in years) between measurements.

At each site, size-dependent growth responses were examined by relating height and/or crown volume increments (absolute growth rate, AGR $\left[\mathrm{ht}_{t_{2}}-\mathrm{ht}_{t 1}\right.$ and $\left.\operatorname{crv}_{t_{2}}-\operatorname{crv}_{t_{1}}\right]$ ) at each of the two surveyed time intervals to plant size at the beginning of these periods using $\log -\log$ linear regression:

$\log \left(\mathrm{AGR}_{\mathrm{t}_{2}-\mathrm{t}_{1}}\right)=a+q \log \left(\right.$ plant size $\left.t_{t_{1}}\right)+c$

where $a$ and $q$ are the intercept and slope parameters, respectively, specific to a given growth interval, and $c$ is the error term. This approach has been used frequently to distinguish between linear, size-proportional and non-linear, size-disproportional increase in growth rate, and to infer an alternative mode of plant interference (Dolezal et al. 2004; Metsaranta and Lieffers 2010; Pretzsch and Dieler 2011). Under this model, if plants grow in proportion to their sizes $\left(q_{1}=1\right)$, thereby depleting limited resources without any individual obtaining a monopoly, then competitive interactions among them are weak and symmetric; if larger individuals grow disproportionately more than others $(q>1)$, thereby pre-empting resources at the expense of smaller plants, then competition is intense and positively size-asymmetric, further increasing size inequality. When $q<1$, growth in smaller plants is disproportionally high relative to their size and growth is inversely size asymmetric; it also implies that the RGR versus initial size relationship is negative, with a higher relative increment in smaller plants than that of larger plants; under this scenario, size inequality can be expected to decrease over time (Dolezal et al. 2004). Standardized major axis (SMA) regressions were carried out to quantify the significance of the departure of $q$ from 1 using SMATR (2.0) software (Warton et al. 2006). SMA 
estimates of lines summarizing the relationship between two variables are superior to the ordinary least square linear regression because residual variance is minimized in both $x$ and $y$ dimensions rather than in the $y$ dimension only (Falster et al. 2003; Warton et al. 2006). The size inequality in growth distribution at the end of each surveyed interval was expressed using the unbiased Gini coefficients (Weiner and Solbrig 1984) which have a minimum value of 0 when growth is evenly distributed, and a theoretical maximum of 1 when growth is highly skewed in favour of one or very few individuals.
Fig. 1 Seed trait (mean $\pm \mathrm{SE}$ ) dynamics of the invasive Lantana camara in each of the four populations surveyed, a soilstored seed abundance, b soil-stored seed germination, and $\mathbf{c}$ fresh seed germination in relation to those experiencing soil burial. Significance of factors tested is also indicated: $* * * P<0.001$, $* * P<0.02, * P<0.05, N S$ not significant, $N A$ no data available
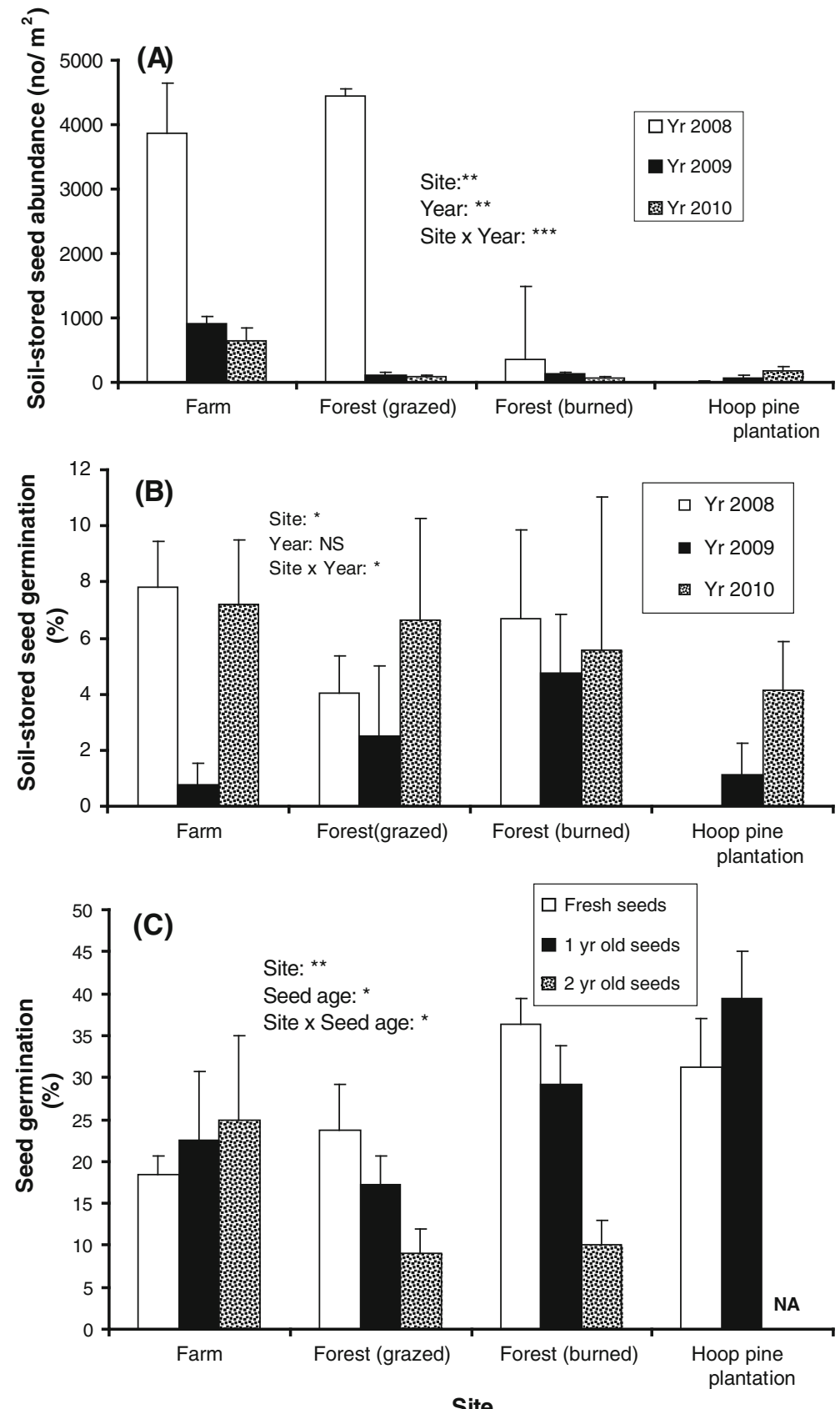


\section{Results}

Seed bank, seed germination and seedling growth

The density of soil-stored seeds, as expected, varied significantly across sites (Fig. 1a). At the initiation of the census, significantly higher numbers of lantana seeds were retrieved from the farm and grazed forest ( $\sim 3,800$ seeds $/ \mathrm{m}^{2}$ ) compared with the burned forest and the hoop pine plantation (359 and $10.0 \mathrm{seeds} / \mathrm{m}^{2}$, respectively) (average across all sites: 1,238 seeds $/ \mathrm{m}^{2}$ ). However, germination of these soil-stored seeds was very low, irrespective of site (range: 0-7.8\%; mean \pm SE: $3.46 \pm 0.69$ ) (Fig. 1b). In subsequent sampling periods, much lower values were obtained for soil-stored seed abundance (306 and $244 / \mathrm{m}^{2}$ for 2009 and 2010; Fig. 1a), while their germination remained low but steady in the range of $2.5-5.9 \%$ (Fig. 1b).

Germination of freshly collected seeds from different sites also varied significantly, with lower values recorded for the population on the farm and in the grazed forest $(\sim 20 \%)$ and moderate values for the remaining two sites (35\%) (Fig. 1c). Interestingly, 1 and 2 years following seed burial and retrieval, almost all seeds remained intact at all sites (proportion recovered: $92-100 \%$ ) and germination remained in the range of $17-40 \%$. At the farm and the hoop pine plantation, there were signs of higher germination of older seeds relative to freshly collected ones (Fig. 1c), while the opposite trend was recorded for buried seeds in the two forests (for the burned forest, a decrease of 19-26\% for 2-year-old seeds compared with fresh or 1 -year-old seeds; for the grazed forest, the decreases were much reduced, $8-14 \%$ ).

Survival of 2-4 week old transplanted seedlings in the first 2 years was moderate to very high (55-88 \%) in all sites, except at the farm where a lower value was obtained (43\%) (Fig. 2). Across sites, growth of these seedlings also mirrored their survival $(r=0.82$; $n=4$ sites; $P=0.09$; Fig. 2 ), with moderate stem height extension (AGR) on the farm $(11.4 \mathrm{~cm} /$ year $)$ and in the burned forest $(8.79 \mathrm{~cm} /$ year $)$ compared with the high stem extension in grazed forest (AGR stem height: $18.8 \mathrm{~cm} /$ year) and an even higher value in the hoop plantation ( $75.5 \mathrm{~cm} /$ year) (see also Table 1). It is also noteworthy that, within a year at the hoop pine plantation (a recolonization site), nine out of 60 ( $\sim 15 \%$ ) of the transplanted seedlings reached maturity and produced viable seeds, suggesting lantana recruits are capable of completing their life cycle within a season in favourable years.

Stem and crown growth as a function of plant size

The RGRs varied significantly between plant stages and sites (Table 1). At all sites, smaller plants (i.e., seedlingjuvenile groups) demonstrated greater height and crown extensions than larger plants (i.e., small-large size reproductive groups), except for RGR-crown volume at the farm population during the 2008-2009 time interval (Table 1). At all sites, growth rates in terms of plant height and crown volume were significantly higher during the wet year (2009-2010) survey period than during the previous (2008-2009) (dry) time interval (Table 1). The exceptions to this trend were lantana populations on the farm (RGR-ht) and in the burned forest (both RGR-height and RGR-crown volume). In the 2008-2009 time interval, RGR-ht was of the order: hoop pine plantation $>>$ burned forest $>$ farm $\geq$ grazed forest (Table 1). By the second time interval (2009-2010), the order was roughly reversed: lantana RGR in grazed forest $>$ burned forest $>>$ farm.

Plant height and crown volume were highly correlated (across sites, $R^{2}=0.68 ; P<0.001$; Fig. 3 ). A plot of AGR in relation to initial value allowed us to explore the nature of growth and competition at each site (Fig. 4; Table 2). Plant crown volume (rather than height) was a better predictor of this trend. In all sites, slope values of the $\log$ initial plant size-log AGR relationship were significantly $<1$, i.e., growth in smaller plants are disproportionally higher relative to their size, signalling inversely size-asymmetric growth. The slopes of the relationship did not differ significantly amongst sites $(q=0.80-0.65 ; P>0.05)$ - suggesting a similar size asymmetry pattern in various land-use types, except for the lantana infestation within the pine plantation (a colonizing population) where the slope value was much lower $(q=0.578$; Table 2). In all populations, the slope values were significantly lower in the wet year interval (2009-2010) compared with the dry year period (2008-2009)—indicating that smaller trees benefit more from the improved moisture conditions. This size inequality in growth, as expressed by the Gini coefficient of crown volume, was highest in the first survey year (2008) and the decreased thereafter with time (comparing 2008-2009 with 2010) and more importantly with increasing stand density, 


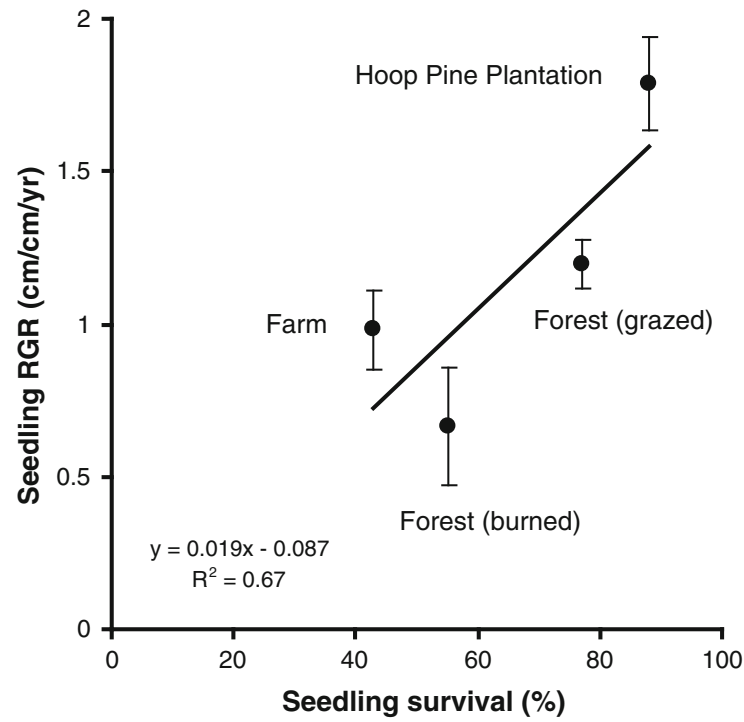

Fig. 2 Performance of 2- to 4-week-old transplanted seedlings of the invasive Lantana camara in terms of growth (RGR) and survival after 2 years in each of the four populations surveyed

especially in the plantation and grazed forest. In addition, it is noteworthy that both the Gini coefficient of AGR and the slope of the log-log plot indi-

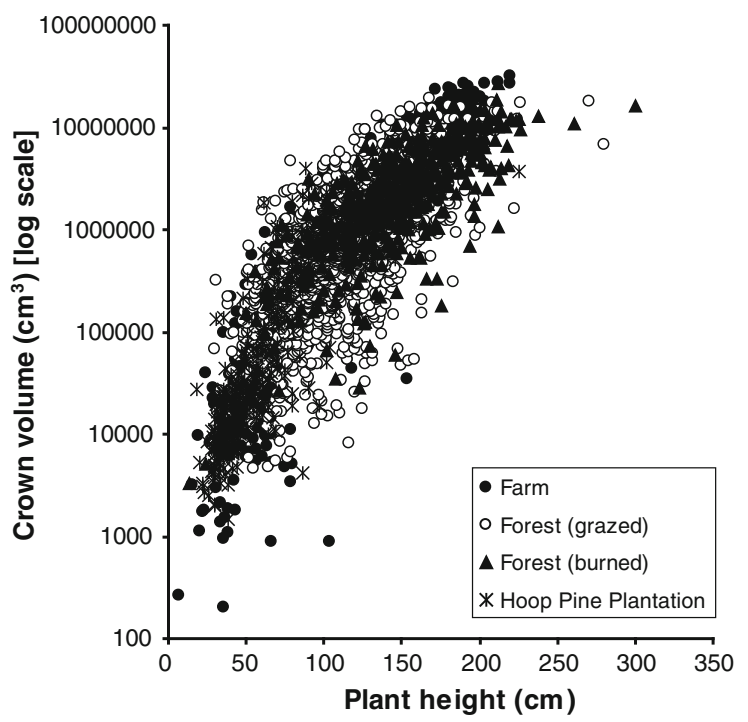

Fig. 3 Relationship between plant height (X) and log crown volume (Y) of Lantana camara at each site. All trends are statistically significant $(P<0.0001)$. The allometric equation describing the trends are: farm, $Y=0.025 X+3.067$ $\left(R^{2}=0.82\right) ; \quad$ forest (grazed), $Y=0.013 X+4.380 \quad\left(R^{2}=\right.$ $0.46)$; forest (burned), $Y=0.011 X+4.671\left(R^{2}=0.58\right)$ and hoop pine plantation $\left(Y=0.020 X+3.470\left(R^{2}=0.62\right)\right.$. Across sites, $Y=0.016 X+3.914\left(R^{2}=0.68\right)$

Table 1 Relative growth rates $( \pm \mathrm{SE})$ of plant height and crown volume at two time intervals for Lantana camara plants grouped by size classes in four populations

\begin{tabular}{|c|c|c|c|c|c|c|c|c|}
\hline \multirow[b]{2}{*}{ Plant stage } & \multicolumn{2}{|l|}{ Farm } & \multicolumn{2}{|c|}{ Forest (grazed) } & \multicolumn{2}{|c|}{ Forest (burned) } & \multicolumn{2}{|c|}{ Hoop pine plantation } \\
\hline & $2008-2009$ & $2009-2010$ & $2008-2009$ & $2009-2010$ & 2008-2009 & $2009-2010$ & 2008-2009 & 2009-2010 \\
\hline \multicolumn{9}{|c|}{ Plant height RGR (cm/cm/year) } \\
\hline Very young seedlings & NA & $0.98(0.13)$ & NA & $1.20(0.08)$ & NA & $0.66(0.19)$ & NA & $1.79(0.15)$ \\
\hline Seedling & $0.27(0.05)$ & $0.41(0.09)$ & $0.37(0.04)$ & $1.25(0.05)$ & $0.85(0.06)$ & - & $1.93(0.05)$ & NA \\
\hline Juvenile & $0.23(0.02)$ & $0.11(0.03)$ & $0.26(0.01)$ & $0.68(0.02)$ & $0.42(0.02)$ & $0.59(0.05)$ & $1.58(0.02)$ & NA \\
\hline Small size adult & $0.11(0.03)$ & $-0.01(0.03)$ & $0.12(0.02)$ & $0.40(0.01)$ & $0.22(0.01)$ & $0.41(0.02)$ & $1.01(0.03)$ & NA \\
\hline Medium size adult & $0.06(0.03)$ & $0.07(0.03)$ & $0.02(0.02)$ & $0.09(0.02)$ & $0.11(0.01)$ & $0.25(0.02)$ & $0.67(0.05)$ & NA \\
\hline Large size adult & $0.01(0.03)$ & $0.05(0.03)$ & $-0.19(0.05)$ & $-0.03(0.05)$ & $-0.07(0.05)$ & $0.19(0.05)$ & $0.08(0.17)$ & NA \\
\hline All plants & $0.14(0.01)^{\mathrm{a}}$ & $0.13(0.02)^{\mathrm{a}}$ & $0.12(0.01)^{\mathrm{a}}$ & $0.48(0.02)^{\mathrm{b}}$ & $0.31(0.02)^{\mathrm{a}}$ & $0.36(0.02)^{\mathrm{a}}$ & $1.05(0.04)$ & NA \\
\hline \multicolumn{9}{|c|}{ Plant crown volume RGR $\left(\mathrm{cm}^{3} / \mathrm{cm}^{3} /\right.$ year $)$} \\
\hline Seedling & $0.03(0.08)$ & $2.51(0.44)$ & $0.03(0.20)$ & $4.85(0.23)$ & $1.70(0.27)$ & - & $5.14(0.24)$ & NA \\
\hline Juvenile & $-0.10(0.15)$ & $2.17(0.18)$ & $0.57(0.07)$ & $2.84(0.08)$ & $1.41(0.06)$ & $1.39(0.19)$ & $4.71(0.10)$ & NA \\
\hline Small size adult & $0.04(0.17)$ & $1.19(0.14)$ & $0.47(0.08)$ & $2.21(0.06)$ & $0.85(0.04)$ & $0.71(0.07)$ & $3.22(0.13)$ & NA \\
\hline Medium size adult & $0.17(0.16)$ & $0.36(0.16)$ & $-0.02(0.11)$ & $1.07(0.09)$ & $0.41(0.06)$ & $0.32(0.06)$ & $2.02(0.20)$ & NA \\
\hline Large size adult & $0.05(0.21)$ & $0.37(0.18)$ & $-0.51(0.26)$ & $0.67(0.21)$ & $0.10(0.20)$ & $0.14(0.21)$ & $0.65(0.76)$ & NA \\
\hline All plants & $0.04(0.09)^{\mathrm{a}}$ & $1.32(0.11)^{\mathrm{b}}$ & $0.11(0.07)^{\mathrm{a}}$ & $2.33(0.07)^{\mathrm{b}}$ & $0.89(0.07)^{\mathrm{a}}$ & $0.64(0.08)^{\mathrm{b}}$ & $3.15(0.17)$ & NA \\
\hline
\end{tabular}

Very young seedlings referred to 2 to 4 -week-old plants with 1-2 pairs of leaves that were transplanted into the field ( $n=60$ per site) in 2009 and monitored for 2 years. We could not conduct the third year (2010) survey on lantana population at the hoop pine plantation site because of canopy closure and impenetrable thicket that developed thereafter and hence data are not available. For pooled plant data within each site, means of yearly periods with the same superscripts are not statistically different at $P \leq 0.05$

$N A$ no data available 

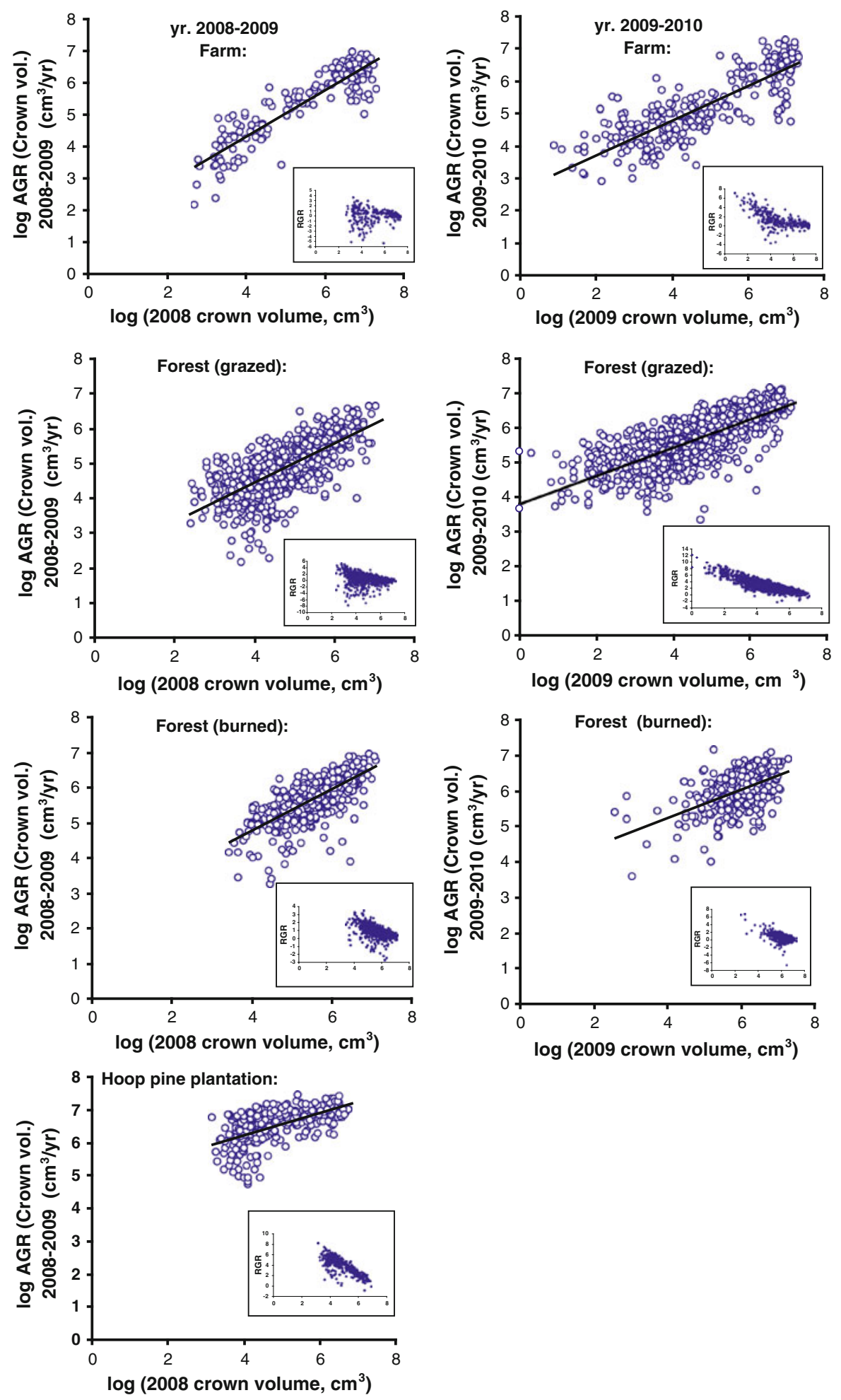

Fig. 4 The influence of initial plant size (crown volume) on absolute growth rate (AGR) of crown volume in the invasive Lantana camara at two time intervals (2008-2009 and

2009-2010). All trends are significant $(P<0.05)$. See Table 2 for exponents of the equations of the relationship. Also shown (as inset) is the RGR versus initial plant size trend 
cated that lantana plants in the hoop pine plantation exhibited the lowest size-asymmetric growth, as expected of a new or a recolonizing population (Table 2; Fig. 4).

\section{Discussion}

Seed bank and seed germination

Overall, our higher soil-stored seed estimate of $\sim 1,000$ seeds $/ \mathrm{m}^{2}$ in the dry period is in line with the hypothesis raised in the "Introduction" section and is similar to values reported for other varieties of lantana by Vivian-Smith et al. (2006). However, there is no doubt that weather conditions affect spatio-temporal abundance of both soil-stored seeds and fresh seed inputs. In the first year of our survey, for sites with minimal disturbance in terms of physical management of the infestation (farm and grazed forest), the lantana seed-bank population was considerable (Fig. 1a), perhaps in response to low rainfall of previous years and thus insufficient moisture for germination (see Table 1). By the second year, the drought event was over, triggering massive germination of soil-stored seeds, with resultant high seedling recruitment, as seen especially in the grazed forest despite the high density of established plants (see Table 1 in Osunkoya et al. 2012). This could thus explain the much lower abundance of soil-stored seeds in subsequent survey periods. However, as we sampled the soil opportunistically once a year, it is possible that our sample periods were not always aligned to the period of adult fecundity, and hence this could affect the estimate of the soil seed bank (see also Vivian-Smith et al. 2006). A more frequent sampling of lantana-infested soils may be required to improve the precision of soil seedbank estimates of this species.

At the burned forest and the hoop plantation, a much reduced lantana seed-bank populations exist, most likely in response to site-specific control treatments applied. The seed-bank population at the burned forest will be expected to remain comparatively low over time because of recurring fire which may kill or promote germination of buried seeds (Raizada and Raghubanshi 2010), whereas that of the hoop pine plantation will likely increase as the lantana population recovers, and indeed this trend has already begun to manifest itself by the third year.
Germination of freshly collected seeds was low to moderate, averaging 25-27\%, and remained in that range or even higher 2-3 years following burial (Fig. 1c). This is a value similar to those reported in Vivian-Smith and Panetta (2009) and Raizada and Raghubanshi (2010), although much more variable, low $(2-10 \%)$ and higher values $(\sim 65 \%)$, have been reported elsewhere (e.g. Gentle and Duggin 1997; Duggin and Gentle 1998, but note that authors reporting higher values treated the seeds to induce germination). The fact that our estimated values remained steady (and even increased in some cases-perhaps due to innate dormancy, after-ripening requirements and/or cold-wet stratification of some sort [Baskin and Baskin 2000]) with burial time corroborates Vivian-Smith and Panetta's (2009) assertion that lantana seeds may remain viable and germinable for a considerable period of time.

It appeared that fire could enhance germination of soil-stored seeds of lantana (see also Raizada and Raghubanshi (2010)). However, in this study, the lack of consistency across sites and between years in the direction and magnitude of such a disturbance regime on seed germination (Fig. 1b, c) suggests that mechanisms other than fire drive lantana seed germination patterns. In addition, fire is likely to decrease adult fecundity, and thus over time, will reduce viability of the lantana population (Osunkoya et al. 2012, 2013).

\section{Plant growth dynamics}

It is not surprising that growth rates irrespective of plant size were the highest for lantana population at the hoop pine plantation (Table 1). This was a site that was selected for the potential to monitor events following clearing of the weed (see Osunkoya et al. 2010, 2013 for simulated long-term population growth rate $(\lambda)$ comparisons of the four study sites). It is, however, noteworthy that the density of this site's soil seed bank was low (Fig. 1a), similar to that of the burned forest-a reflection of mass germination and/or delay (time lag) in fresh seed-input into the soil at this site following the removal of the weed.

As expected, the growth rate decreased with increasing plant size both on plant height and crown volume bases (Fig. 4; Table 1). The low intensity triennial fire in the burned forest adversely affected survival of only very young plants (see Osunkoya et al. 2012), and though it reduced growth at this site 
compared with other sites (see Figs. 2, 3; Table 1), the treatment is incapable of reducing the RGR below the tipping point (i.e., creating a negative RGR) or achieving a negative annual population growth rate (Osunkoya et al. 2010, 2013). Thus, the use of fire as a long-term management strategy calls for greater burning frequency if the intention is beyond just to arrest plant growth (see also Swarbrick et al. 1995). However, as expected, burning did result in the lowest size asymmetry of growth of all populations surveyed.

All intercept values of the AGR-size relationships are positive, indicating that plants are competing more for below-ground rather than above-ground (light) resources (see Pretzsch and Biber 2010). The fact that asymmetries of AGR and crown volume (Gini coefficients) were the greatest in the grazed forest (a site with the highest plant density; see Table 2; Osunkoya et al. 2012) supports the notion that size asymmetry of growth increases with density in crowded populations (Weiner and Damgaard 2006; Méndez-Alonzo et al. 2012). The lack of significant changes in the asymmetry of crown volume and AGR with time of lantana plants on the farm, just as observed for its unusual bimodal size distribution (see Osunkoya et al. 2012) is worth commenting upon. A static asymmetric-growth pattern has been argued to develop in populations approaching the linear growth phase of the sigmoid population growth curve (Weiner 1990), and where density and competition effects are minimal (Weiner and Damgaard 2006). This is probably true for lantana on the farm as both the density and growth rates were lowest among of all the surveyed sites (see Osunkoya et al. 2012); competition for light can also be discounted as the habitat is open. The observed significant drop in slope values of the log AGR-log initial size (irrespective of sites) confirms the notion that the mode of size growth relationship (and competition) can change within a stand in response to annual weather and/or limitation by below-ground resources (Schwinning and Weiner 1998; Pretzsch and Dieler 2011). Thus with $q<1$ and decreasing with time, it appears that smaller lantana plants benefited more from increasing moisture conditions. This finding failed to support our hypothesis that large lantana plants will consistently perform better than smaller ones relative to what would be expected based solely

Table 2 Lantana camara stand density, nearest neighbour (NN) distance, growth asymmetry (Gini coefficients) and parameter estimates using standardised major regression of

$\log -\log$ relationship of absolute growth rates (AGR) of crown versus initial plant size (crown volume); $R^{2}$ percentage variation explained

\begin{tabular}{|c|c|c|c|c|c|c|c|c|c|}
\hline \multirow[t]{2}{*}{$\begin{array}{l}\text { Site and plot } \\
\text { size }(\mathrm{m})\end{array}$} & \multirow[t]{2}{*}{$\begin{array}{l}\text { Survey } \\
\text { (years) }\end{array}$} & \multirow[t]{2}{*}{$\begin{array}{l}\text { No. of } \\
\text { plants }\end{array}$} & \multirow[t]{2}{*}{$\begin{array}{l}\text { Mean density } \\
\left(\text { no. } / 100 \mathrm{~m}^{2}\right)^{\mathrm{a}}\end{array}$} & \multirow{2}{*}{$\begin{array}{l}\text { Nearest } \\
\text { neighbor } \\
\text { distance }(m)^{b}\end{array}$} & \multicolumn{2}{|c|}{ Gini coefficient } & \multicolumn{3}{|c|}{$\begin{array}{l}\log (\text { AGR crown volume, } Y) \text { versus } \\
\log (\text { initial crown volume, } X)\end{array}$} \\
\hline & & & & & $\begin{array}{l}\text { Crown } \\
\text { volume }\end{array}$ & AGR & $\begin{array}{l}\text { Slope }(q) \\
( \pm 95 \% \mathrm{CI})\end{array}$ & $\begin{array}{l}\text { Intercept } \\
\text { (a) }\end{array}$ & $R^{2}$ \\
\hline \multirow{3}{*}{$\begin{array}{l}\text { Farm } \\
\qquad(50 \mathrm{~m} \times 50 \mathrm{~m})\end{array}$} & 2008 & 286 & 11.44 & 0.97 & 0.710 & & & & \\
\hline & 2009 & 342 & 13.68 & 0.96 & 0.741 & 0.737 & $0.799(0.749-0.852)$ & 0.999 & $0.82 * * *$ \\
\hline & 2010 & 409 & 16.36 & 0.89 & 0.724 & 0.754 & $0.638(0.599-0.670)$ & 2.120 & $0.71 * * *$ \\
\hline \multirow{3}{*}{$\begin{array}{l}\text { Grazed forest } \\
\qquad(30 \mathrm{~m} \times 50 \mathrm{~m})\end{array}$} & 2008 & 1,045 & 80.38 & 0.48 & 0.822 & & & & \\
\hline & 2009 & 1,291 & 99.31 & 0.40 & 0.818 & 0.774 & $0.805(0.763-0.849)$ & 1.039 & $0.481 * * *$ \\
\hline & 2010 & 1,414 & 108.96 & 0.32 & 0.647 & 0.609 & $0.545(0.525-0.565)$ & 3.160 & $0.565 * * *$ \\
\hline \multirow{3}{*}{$\begin{array}{l}\text { Burned forest } \\
\qquad(50 \mathrm{~m} \times 50 \mathrm{~m})\end{array}$} & 2008 & 602 & 24.08 & 0.79 & 0.655 & & & & \\
\hline & 2009 & 620 & 24.08 & 0.77 & 0.596 & 0.557 & $0.831(0.783-0.888)$ & 1.081 & $0.509 * * *$ \\
\hline & 2010 & 546 & 21.84 & 0.76 & 0.521 & 0.525 & $0.779(0.713-0.851)$ & 1.390 & $0.202 * *$ \\
\hline \multirow{3}{*}{$\begin{array}{l}\text { Hoop pine } \\
\text { plantation } \\
(40 \mathrm{~m} \times 50 \mathrm{~m})\end{array}$} & 2008 & 362 & 18.11 & 0.77 & 0.811 & & & & \\
\hline & 2009 & 1,926 & 96.33 & 0.42 & 0.485 & 0.473 & $0.578(0.529-0.632)$ & 3.738 & $0.286 * * *$ \\
\hline & 2010 & & - & - & - & - & - & & - \\
\hline
\end{tabular}

All slope values were significantly $(P<0.05)$ lower than 1 . Survey year interval of 2008-2009 experienced significant moisture stress, while 2009-2010 typifies a moisture-abundant period

a,b Data extracted from Tables 2 and 3 of Osunkoya et al. 2012 but presented herewith improved clarity and for better understanding of these traits with growth allometry

$* * * P<0.001 ; * * P<0.02$ 
on differences in size. We are not aware of this kind of study for invasive woody plants, but it does point to reduced intraspecific competition (especially in smaller individuals) in lantana stands. Such a phenomenon may partly explain the success of lantana across varying landscapes it invades. Nonetheless, the study did not explicitly take into account the effects of stand density, plant size and proximity of neighbours on the degree of asymmetry reported in this article. Such measures of local interference (see Thomas and Weiner 1989; Dolezal et al. 2009) on individual plant performance are crucial to fully elucidate the mode of growth and nature of intra- and inter-specific competition in a given stand, and will be the focus of another study.

\section{Conclusions}

We have provided lantana plant height-crown volume allometry-a relationship that can estimate standing biomass of the weed and has utility for better field quantification of success of control measures, including bio-control efficacy. We have shown that the dynamics of lantana population structure, including its seed bank, growth and stand size asymmetry vary in time and space. Density has an appreciable effect on fecundity and growth (see Osunkoya et al. 2012), but surprisingly, has minimal influence on survival within and across lantana populations - a finding also reported by Raizada and Raghubanshi (2010). For the very small (transplanted) seedlings, we found that an expected trade-off in two life-history traits (survival and growth) did not manifest in lantana populations, and thus the observed positive association between these two traits, coupled with a persistent seed bank, could contribute to the invasiveness of the plant (see also Martin et al. 2010). Nearly a quarter of fresh seeds remain germinable after 3 years, confirming that seeds are relatively persistent. Periodic but low-intensity burning of a lantana population will not tilt the population towards negative growth (see also Osunkoya et al. 2010), although it can reduce plant size asymmetry and the abundance and germinability of its soil-stored seeds. Our results support the hypothesis that variation in precipitation during a given growth period influences growth pattern and size asymmetry, and possibly the nature of competition, though we failed to detect any increase in size variability with increasing moisture as hypothesized in the "Introduction" section. Relationships between AGR and initial plant size appeared to be positively linear, suggesting that most populations are still at varying stages of the exponential phase of sigmoid growth; the trend also suggest that lantana growth is inversely size asymmetric, with higher RGR for smaller plants, indicative of reduced intraspecific competition that appeared to be insensitive to stand density and limiting environmental resources. For the lantana infestation on the farm, the cause and consequence of the observed distinctive growth trajectory, including invariant size asymmetry and bimodality (see Osunkoya et al. 2012), is worth investigating further for greater understanding of site-specific population persistence, invasiveness and/or control. Also, because of financial and logistic constraints, we lack replication of the land-use types surveyed. Thus, the generality of our findings needs to be scrutinized further using more sites that span the invaded range of the focal species.

Acknowledgments The research was funded by the Queensland Land Protection Council and by the Australian Federal Government through its Weeds of National Significance (WONS) program for Lantana camara. The authors thank Dane Panetta for the comments on drafts of this paper.

\section{References}

Arenas F, Viejo RM, Fernández C (2002) Density-dependent regulation in an invasive seaweed: responses at plant and modular levels. J Ecol 90:820-829

Baskin CC, Baskin JM (2000) Seeds: ecology, biogeography and evolution of dormancy and germination. Elsevier, The Netherlands

Dolezal J, Ishii H, Vetrova VP, Sumida A, Hara T (2004) Tree growth and competition in a Betula platyphylla-Larix cajanderi post-fire forest in Central Kamchatka. Ann Bot 94:333-343

Dolezal J, Song J-S, Altman J, Janecek S, Cerny T, Srutek M, Kolbek J (2009) Tree growth and competition in a postlogging Quercus mongolica forest on Mt. Sobaek, South Korea. Ecol Res 24:281-290

Duggin JA, Gentle CB (1998) Experimental evidence on the importance of disturbance intensity for invasion of Lantana camara L. in dry rainforest-open forest ecotones in northeastern NSW, Australia. For Ecol Manag 109:279-292

Falster DS, Warton DI, Wright IJ (2003) Standardized major axis tests and routines ((S)MATR). http://www.bio.mq. edu.au/SMATR. Accessed July 2012

Gentle CB, Duggin JA (1997) Allelopathy as a competitive strategy in persistent thickets of Lantana camara L. in three Australian forest communities. Plant Ecol 132:85-95 
Gioria M, Pysek P, Moravcova L (2012) Soil seed banks in plant invasions: promoting species invasiveness and long-term impact on plant community dynamics. Preslia 84:327-350

Gooden B, French K, Turner PJ (2009) Invasion and management of a woody plant, Lantana camara L., alters vegetation diversity within wet sclerophyll forest in southeastern Australia. For Ecol Manag 257:960-967

Lowe S, Browne M, Boudjelas S, De-Poorter M (2004) One hundred of the world's worst invasive alien species: a selection from the global invasive species database. Invasive Species Specialist Group, IUCN, Switzerland

Martin PH, Canham CD, Kobe RK (2010) Divergence from the growth-survival trade-off and extreme high growth rates drive patterns of exotic tree invasions in closed-canopy forests. J Ecol 98:778-789

Méndez-Alonzo R, Hernández-Trejo H, López-Portillo J (2012) Salinity constrains size inequality and allometry in two contrasting mangrove habitats in the Gulf of Mexico. J Trop Ecol 28:171-179

Metsaranta JM, Lieffers VJ (2010) Patterns of inter annual variation in size asymmetry of growth of Pinus banksiana. Oecologia 163:737-745

Osunkoya, OO, Perrett C, Fernando C, Clark C, Raghu S (2013) Modeling population growth and site specific control of the invasive Lantana camara 1 (Verbenaceae) under differing fire regimes. Popul Ecol 55:291-303

Osunkoya OO, Perrett C (2011) Lantana camara L. (Verbenaceae) invasion effects on soil physicochemical properties. Biol Fertil Soils 47:349-355

Osunkoya OO, Perrett C, Fernando C (2010) Population viability analysis models for Lantana camara L. (Verbenaceae): a weed of national significance. In: Zydenbos SM (ed) Proceedings of the 17th Australasian Weeds Conference, New Zealand Plant Protection Society, Christchurch, pp 91-94

Osunkoya OO, Perrett C, Fernando C, Clark C, Raghu S (2012) Stand dynamics and spatial patterns across varying sites in the invasive Lantana camara L. (Verbenaceae). Plant Ecol 213:883-897

Pretzsch H, Biber P (2010) Size-symmetric versus size-asymmetric compétition and growth partition among forest trees in forest stands along an ecological gradients in central Europe. Can J Forest Res 40:370-384
Pretzsch H, Dieler J (2011) The dependency of the size-growth relationship of Norway Spruce (Picea abies [L.] Karst.) and European beech (Fagus sylvatica [L.]) in forest stands on long-term site conditions, drought events, and ozone stress. Trees 25:355-369

Raizada P, Raghubanshi A (2010) Seed germination behavior of Lantana camara in response to smoke. Trop Ecol 51(2): 347-352

Sahu AK, Panda S (1998) Population dynamics of a few dominant plant species around industrial complexes, in West Bengal, India. Bombay Nat Hist Soc J 95:15-18

Schwinning S, Weiner J (1998) Mechanisms determining the degree of size-asymmetry in competition among plants. Oecologia 113:447-455

Swarbrick JT, Willson BW, Hannan-Jones M (1995) Lantana camara L. Plant Prot Q 10:82-95

Thomas SC, Weiner J (1989) Gowth, death and size distribution change in Impatiens pallida population. J Ecol 77:524-536

Vega CRC, Sadras VO (2003) Size dependent growth and the development of inequality in maize, sunflower and soybean. Ann Bot 91:795-805

Vivian-Smith G, Panetta FD (2009) Lantana (Lantana camara) seed bank dynamics: seedling emergence and seed survival. Inv Plant Sci Manag 2:141-150

Vivian-Smith G, Gosper CR, Wilson A, Hoad K (2006) Lantana camara and the fruit- and seed-damaging fly, Ophiomyia lantanae (Agromyzidae): seed predator, recruitment promoter or dispersal disrupter? Biol Control 36:247-257

Warton DI, Wright IJ, Falster DS, Westoby M (2006) Bivariate line fitting methods for allometry. Biol Rev 81:259-291

Weiner J (1990) Asymmetric competition in plant populations. Trends Ecol Evol 5:360-364

Weiner J, Damgaard C (2006) Size-asymmetric competition and size-asymmetric growth in a spatially explicit zone-ofinfluence model of plant competition. Ecol Res 21:707-712

Weiner J, Solbrig OT (1984) The meaning and measurements of size hierarchies in plant populations. Oecologia 3:334-336

Wiegard K, Ward D, Saltz D (2005) Multi-scale patterns and bush encroachment in an arid savanna with a shallow soil layer. J Veg Sci 16:311-320

Zimmerman JK, Pascarella JB, Aide TM (2000) Barriers to forest regeneration in an abandoned pasture in Puerto Rico. Restor Ecol 8:328-338 
Reproduced with permission of the copyright owner. Further reproduction prohibited without permission. 